Portland State University

PDXScholar

$5-3-1983$

Comprehension of Abstract and Concrete Commands by High and Low Level Aphasic Subjects : Effects of Presentation Mode

Karen Jaruckis Lambrecht Portland State University

Follow this and additional works at: https://pdxscholar.library.pdx.edu/open_access_etds

Part of the Speech Pathology and Audiology Commons Let us know how access to this document benefits you.

Recommended Citation

Lambrecht, Karen Jaruckis, "Comprehension of Abstract and Concrete Commands by High and Low Level Aphasic Subjects : Effects of Presentation Mode" (1983). Dissertations and Theses. Paper 3351.

https://doi.org/10.15760/etd.5009

This Thesis is brought to you for free and open access. It has been accepted for inclusion in Dissertations and Theses by an authorized administrator of PDXScholar. Please contact us if we can make this document more accessible: pdxscholar@pdx.edu. 
AN ABSTRACT OF THE THESIS OF Karen Jaruckis Lambrecht for the Master of Science in Speech Communication, with an emphasis in Speech-Language Pathology/Audiology, presented May 3, 1983. Title: Comprehension of Abstract and Concrete Commands by High and Low Level Aphasic Subjects: Effects of Presentation Mode.

APPROVED BY MEMBERS OF THE THESIS COMMITTEE:
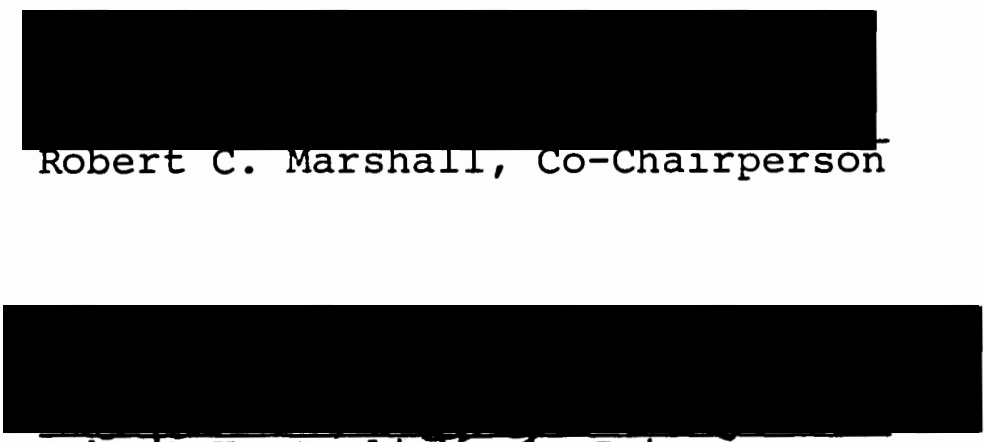

Robert H. English, /o-Cairperson

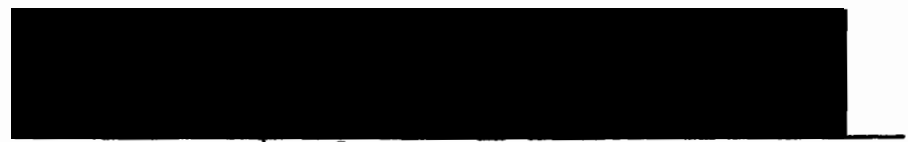

Mary E. Gordon

This study examined the influence of three presentation modes (live voice, tape recorded, and videotape recorded) on aphasic subjects' comprehension of concrete and abstract commands.

Twelve aphasic adults were assigned to high or low 
comprehension groups according to their performance on the Token Test described by Boller and Vignolo (1966). Six subjects who committed from 30-60 percent errors on Part II comprised the low comprehension group. Six subjects who failed 30-60 percent of the items on Part IV of the test made up the high comprehension group.

Each subject was administered two, ten-item tasks (abstract and concrete) in three presentation modes. The abstract tasks for high comprehension subjects consisted of Part IV of the Token Test, which involves responding to commands requiring the patient to manipulate twenty tokens of two shapes (circle and square), five colors (red, blue, green, white, yellow), and two sizes (big and little). For low comprehension subjects the abstract tasks consisted of Part II of the Token Test which involved responding to commands requiring the patient to manipulate only ten tokens. The concrete tasks for both groups of subjects were identical to the abstract tasks with the exception that the tokens were replaced with pictures of houses and flowers of equivalent size and color. For each presentation mode, the concrete tasks were presented first. Ordering of presentation modes was counterbalanced across subjects. Subjects' responses were scored using both plus-minus and weighted systems.

Data were submitted to a three-way Analysis of Variance which considered the effects of groups (low comprehension versus high comprehension), difficulty (abstract versus concrete), presentation mode (live, taped, videotaped), and the 
interactions among these variables. As anticipated, subjects performed significantly better on concrete than abstract commands. Differences between groups, and presentation modes, however, were not significant. Clinical implications emerging from this study are: 1) the Token Test could possibly be delivered via tape recorder to standardize presentation; 2) computerized videotape and audiotape recorded presentations might be efficaciously employed in auditory comprehension training for certain aphasic patients; and 3) the effects of mode of presentation in conjunction with other auditory comprehension facilitators needs to be investigated. 


\title{
COMPREHENSION OF ABSTRACT AND CONCRETE COMMANDS BY HIGH AND LOW LEVEL APHASIC SUBJECTS: EFFECTS OF PRESENTATION MODE
}

\author{
by
}

KAREN JARUCKIS LAMBRECHT

A thesis submitted in partial fulfillment of the requirements for the degree of

MASTER OF SCIENCE IN SPEECH COMMUNICATION: with and emphasis in SPEECH-LANGUAGE PATHOLOGY/AUDIOLOGY 
TO THE OFFICE OF GRADUATE STUDIES AND RESEARCH:

The members of the Committee approve the thesis of Karen Jaruckis Lambrecht presented May 3, 1983.

Robert C. Marshall, Co-Chairperson
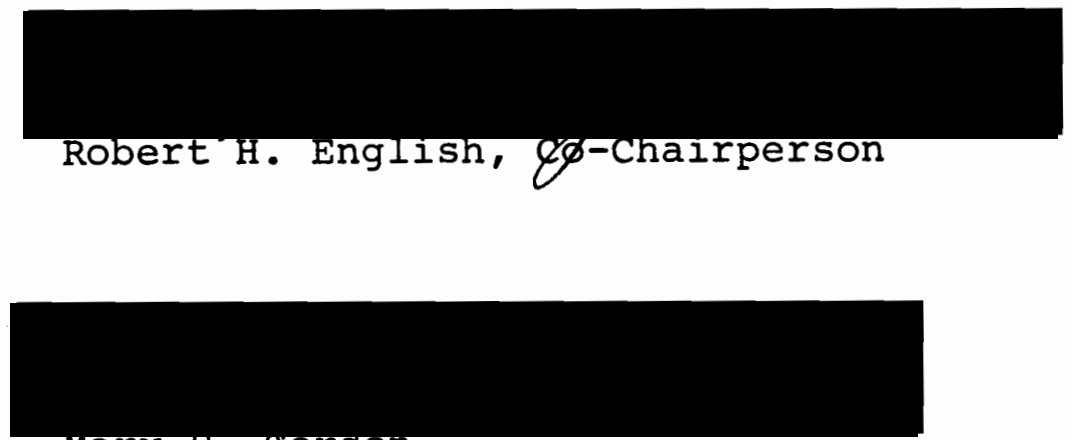

Mary E. goraon

APPROVED :

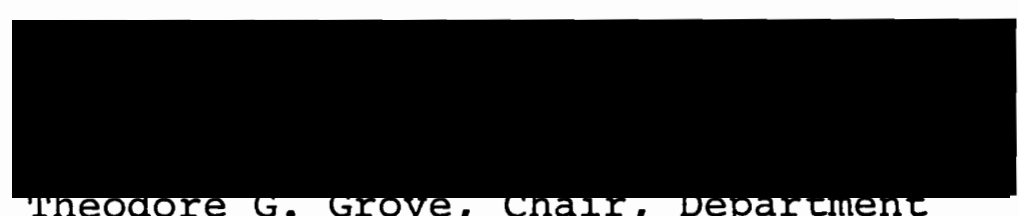

of Speech Communication

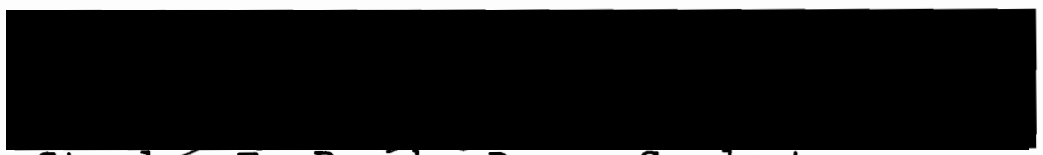

Stanley E. Rauch, Dean, Graduate

Studies and Research 


\section{ACKNOWLEDGEMENTS}

I wish to express my sincere thanks and appreciation to several encouraging friends and cohorts who helped to complete this thesis:

Dr. Robert C. Marshall for his guidance, support, and constant encouragement. Without his assistance, this thesis would not have been possible.

Dr. Robert H. English and Ms. Mary Gordon for their helpful suggestions and editing during the preparation of this manuscript.

Dr. Dan Grey for his aid in the statistical computation of the data.

My thesis subjects who very generously gave of their time and energy to participate in the study.

Finally, I owe much gratitude to a group of supportive friends -- Doug, Connie, Cheryl, Deborah, Sandra, Stephen, and Leonard. Thanks for your patience, interest, and confidence over the past years. 
TABLE OF CONTENTS

Page

ACKNOWLEDGEMENTS

LIST OF TABLES

$\mathrm{v}$

CHAPTER

I INTRODUCTION AND STATEMENT OF PURPOSE $\cdot$. . $I$

Introduction . . . . . . . . . . . 1

Statement of Purpose ......... 3

Definition of Terms ......... 3

II REVIEW OF THE IITERATURE . . . . . . . 5

Background to Auditory Comprehension Deficits ............ . 5

Specific Auditory Processing Deficits ........... . 7

Importance of Message Delivery . . . . 10

Major Message Delivery Techniques . . . 11

summary ............. 28

III METHODS AND PROCEDURES . . . . . . . . 29

Subjects . . . . . . . . . . 29

Tasks ............... . 32

Presentation Modes .. . . . . . . 32

Procedures ............. . 33

Scoring . . . . . . . . . . . . 33

Data Analysis . . . . . . . . . 34

IV RESULTS AND DISCUSSION . . . . . . . 35

Results ............. 35

Discussion

$\mathrm{V}$ SUMMARY AND IMPLICATIONS . . . . . . . 41

Summary . . . . . . . . . . . . 41

Clinical Implications :. . . . . . . 42

Research Implications ......... 43

BIBLIOGRAPHY . . . . . . . . . . . . . 45

APPENDICES ................... . . 53 


\section{LIST OF TABLES}

TABLE

Page

I Description of Aphasic Subjects . . . . . . . 31

II Summary of Analysis of Variance for plus-Minus Scores . . . . . . . . . 36

III Summary of Analysis of Variance for Weighted Scores . . . . . . . . . . 37 
CHAPTER I

INTRODUCTION AND STATEMENT OF PURPOSE

Introduction

Aphasia is an impairment in the interpretation and formulation of language symbols. This disruption of language processing is due to brain damage and constitutes a multimodal disorder involving a loss or reduction of listening, reading, speaking, and writing abilities (Darley, 1969). Clinical and experimental evidence indicates the auditory processes are always impaired to some degree in aphasia (Marie, 1906; Weisenberg and McBride, 1935; DeRenzi and Vignolo, 1962; Schuell, Jenkins, and Jiminez-Pabon, 1964). Impairments in auditory verbal retention and comprehension have been found to affect the aphasic individual's performance in all language modes and to be detrimental to his interactions within his environment. The importance of the auditory system to language learning and re-acquisition has stimulated the use of intensive auditory stimulation as a basic approach to aphasia treatment.

In the past two decades the auditory comprehension difficulties of aphasic persons have received particularly close scrutiny from aphasia clinicians and researchers. Several factors have been isolated that have been shown to influence 
aphasic individual's auditory comprehension performance. Some of these include syntactic complexity, semantic relatedness, message length, vocabulary, message redundancy, stress, and markedness. Generally, aphasic clients' comprehension of verbal stimuli is facilitated by the use of briefer, less complex messages with a high degree of linguistic redundancy or within which elements critical to understanding are marked or stressed. Substantial evidence also exists that illustrates aphasic individuals comprehend better when messages are delivered at slower presentation rates.

It follows that clinical suggestions for treatment of auditory comprehension deficits emphasize that the clinician control or systematically manipulate the aforementioned variables to heighten aphasic patients' comprehension performance (Duffy, 1981; Marshall, 1981, 1978; Darley, 1976). Auditory comprehension training, however, takes time and effort. In this vein, it is surprising that little attention has been given to the factor of presentation mode and its potential influence on aphasic persons' comprehension performance. Three presentation modes are currently available to the practicing clinician for auditory comprehension training. The most common is live voice (face-to-face) presentation; however, tape recorded presentations, and, more recently, videotape recorded presentations have been used in auditory comprehension training as well. Unfortunately, the influence of different presentation modes on the comprehension of aphasic individuals has not been systematically examined. The only 
available information suggesting that presentation mode might make a difference emanates as a tangential finding of two previous investigations by Green and Boller in 1974 and Boller, Cole, Vrtunski, Patterson, and Kim in 1979. In both of these studies severely impaired aphasic adults responded better to commands, yes/no, and information questions presented with live voice than with taped voice, especially when the examiner was seated in front of rather than behind the subject. Information as to the efficacy of videotape presentation on comprehension by aphasic subjects is not available.

\section{Statement of Purpose}

The purpose of this investigation was to examine the influence of tape recorded, videotaped, and live presentation modes on the auditory comprehension of aphasic subjects.

This investigation sought to answer the following questions:

1. Does the mode of presentation affect low-level aphasic adults' auditory comprehension of abstract and concrete commands?

2. Does the mode of presentation affect high-level aphasic adults' auditory comprehension of abstract and concrete commands?

Definition of Terms

For the purpose of this study the following operational definitions were utilized.

Auditory Comprehension: auditory comprehension involves the perception, retention, and association of meaning of auditory information (Yorkston, Marshall, and Butler, 1977). 
Auditory Comprehension Impairment: auditory comprehension impairment refers to an inability to understand linguistic utterances that cannot be attributed to sensory input deficits, generalized cognitive deficits, or defects in attention (Boller, Kim, and Mack, 1977).

Auditory Stimulation: auditory stimulation involves providing a subject with a verbal message to elicit a non-verbal response. The message may be supplemented with visual or gestural input and delivered by tape recorder or live voice, but the auditory pathway is always implicated. Auditory stimulation constitutes the foundation of aphasia treatment (Marshall, 1978). 
CHAPTER II

REVIEW OF THE LITERATURE

Background to Auditory Comprehension Deficits

Nearly all aphasic subjects demonstrate some degree of impairment of the auditory processes (Marie, 1906; Weisenberg and McBride, 1935; DeRenzi and Vignolo, 1962; Schuell, Jenkins, Jimenez-Pabon, 1964). Auditory processing deficits affect the patient's comprehension of all types of verbal messages. Unfortunately, these deficits are difficult to measure because their existence can only be inferred from the patient's overt response to what he hears (Riedel, 1981). Detailed analyses of aphasic patients' comprehension deficits suggest, however, that the processes of auditory comprehension are separable and amenable to investigation and that impairments of certain processes, resulting from brain damage, are reflected by particular behaviors (Green and Boller, 1974). Recently acquired knowledge reveals that aphasic subjects appear to respond differently to varying stimuli and to be differentially affected by particular communicative situations. More specifically, the auditory comprehension difficulties exhibited by aphasic patients are not all alike (Schuell et al., 1964; Luria, 1966; Brookshire, 1974; Marshall, 1981). Treatment of auditory processing deficits is best directed, 
therefore, towards determining the nature and extent of the patient's comprehension impairment, and the use of selected combinations of facilitating techniques to heighten auditory comprehension (Marshall, 1981).

There are many facilitating techniques available to the practicing clinician that may enhance the aphasic person's comprehension of spoken messages. An understanding of the factors that influence auditory comprehension of aphasic individuals is of considerable interest for both clinical and theoretical reasons. Theoretically, knowledge of factors related to how aphasic listeners handle auditory information is critical in the construction of a model of the auditory comprehension process. Clinically, it is essential to know which factors enhance auditory comprehension and which affect it detrimentally (Yorkston, Marshall, and Butler, 1977).

There is a considerable body of literature attempting to describe the various types and patterns of auditory comprehension deficits of specific aphasic syndromes. The present chapter, however, reviews only that literature most closely associated with the problem under investigation, namely procedures or techniques that facilitate or inhibit auditory comprehension. Primary consideration will be given therefore, to a review of specific auditory processing deficits and the major message delivery techniques discussed in the aphasia literature. 


\section{Specific Auditory Processing Deficits}

Brookshire (1972, 1974) has delineated five possible types of auditory processing deficits that underscore the need to consider auditory processing deficits in aphasia as more than a unitary problem. These deficits and some implications for stimulus selection are discussed in the following section.

The patient who exhibits slow rise time tends to miss the initial portion of the verbal message because his processing system takes more than the normal amount of time to shift from a passive to an active processing state (Brookshire, 1978a). This particular response pattern may be the result of two specific problems. The individual with an attentional deficit is unprepared for the incoming verbal message, and his comprehension may be facilitated by placing key elements of the message at the end of the sentences or by the use of an introductory or warning phrase or any other alerting signal (e.g., "Now, listen to this.", "Are you ready?"). The individual with an inertial deficit has difficulty shifting from an inactive to an active processing state; however once the switch is made, his comprehension is usually quite good. The alerting signals used with patients presenting an attentional deficit may not be as useful with these patients. Marshall (1981) suggests delivering successive verbal messages in close proximity so as to inhibit the individual's auditory system from returning to a passive state. 
The patient whose auditory system is affected by noise build-up tends to deteriorate in performance from the beginning to the end of a message, or across a series of messages (Porch, 1967). Brookshire (1978a) indicates that the rate at which the "noise" in the patient's system accumulates appears to be related to the complexity of the message. Complex messages tend to generate more noise and to generate it earlier than less complex utterances. He suggests that a rest period, or switching to easier tasks, will frequently counteract noise build-up.

Individuals with a retention deficit also exhibit poorer performance as the length of the verbal message is increased. Message complexity, however, does not appear to greatly affect their performance; rather their systems tend to turn-off at about the same point in all messages, regardless of the complexity of the message (Brookshire, 1974). Therefore, the patient with a retention deficit performs as poorly on repetition tasks as on comprehension tasks, while the patient with noise build-up performs better on repetition tasks. Brookshire (1974) suggests that treatment of the individual with a retention deficit involves gradually increasing the length of messages which must be processed.

The aphasic patient with an information capacity deficit has difficulty receiving and processing verbal messages simultaneously (Wepman, 1972). Brookshire (1974) has observed that the performance of these patients tends to be alternately good and poor within a message. They tend to do better 
on the initial and final items of a series than on the middle portion. From a treatment standpoint, these patients differ from those individuals with retention deficits in that they benefit from insertions of brief, silent pauses at strategic intervals within a message (Brookshire, 1978b).

The patient with intermittent auditory imperception appears to fade in and out in terms of comprehension of the incoming message (Schuell, 1965; Brookshire, 1974). Schuell indicates that these periods of imperception may last from a few seconds to several minutes, during which time the patient behaves as if he were deaf. Marshall, Jeffries, Rau, Golper, and Thomas (1976) suggest intermittent auditory imperception results from a combination of central and transmissive processing difficulties. They recommend that treatment focus on: 1) communication in context; 2) elimination of variables associated with imperceptive states; 3) provision of combined auditory-visual stimulation; and 4) control of the patient's excessive verbalizations.

Brookshire (1974) points out that the auditory processing deficits mentioned in this section do not usually appear in pure form but in various combinations. He also cautions that this list of auditory processing deficits may be incomplete. Major investigators repeatedly refer to the need for detailed analysis of the aphasic individual's performance, so the extent and nature of the patient's language comprehension deficits may be accurately described (Schuell, 1965; Luria, 1966; Brookshire, 1974). 
Importance of Message Delivery

As speech-language clinicians have become more knowledgeable and proficient in assessment of the types and patterns of auditory processing deficits, they are particularly concerned with the establishment of appropriate treatment regimes to improve or compensate for these problems. A number of published accounts documenting the benefits of intensive auditory stimulation can be found in the aphasia literature (West, 1973; Holland and Sonderman, 1974; Czvik, 1976; Kushner and Winitz, 1977). Marshall (1978) defines auditory stimulation as a means of providing the aphasic individual with a verbal message to elicit a non-verbal response. The message may be augmented by visual or gestural input and delivered by live or taped voice, but the auditory pathway is always involved. In a typical treatment session, a variety of clinician-client interchanges occur, placing a large number of auditory comprehension demands on the aphasic patient. In delivering the verbal stimulus, the clinician must carefully regulate the message so that it is neither too simple nor too difficult, but is sufficiently complex to stimulate disrupted auditory processes.

A vast amount of information has been collected about stimulus variables that may affect an aphasic individual's performance. These data originate from basic clinical and experimental research and are not primarily attributed to specific treatment studies (Duffy, 1981). Nevertheless, they 
provide valuable information to the clinicians who observe and analyze patients' responses to auditory stimulations; attend to situational, psychological, and physiological factors that influence responsivity; and decide when to make the necessary alterations in message delivery or content, so as to maximize auditory input.

\section{Major Message Delivery Techniques}

There are several techniques that may be employed by the clinician to facilitate comprehension of verbal messages. This section reviews some of the major message delivery techniques and summarizes how the use of these procedures affects the auditory comprehension abilities of aphasic persons. Marshall (1981) has grouped these variables affecting auditory comprehension under three categories: linguistic; timing; and contextual variables.

\section{Linguistic Variables}

Schuell et al. (1964) point out that the linguistic characteristics of a verbal message have the most noticeable influence on aphasic patients' comprehension. Reduction of available vocabulary, loss of linguistic rules, decreased auditory-verbal retention span, as well as impaired comprehension and production of messages were considered by schuell to be the salient characteristics of aphasia (Schuell, 1969; 1974a; Schuell and Jenkins, 1961; Schuell et al., 1964). The information in the following section provides a 
discussion of those linguistic variables that may affect auditory comprehension of aphasic adults.

\section{Message length. The fact that most aphasic clients} have a reduced verbal retention span highlights the importance of length as a stimulus factor and has received support from a number of sources, including aphasic patients themselves (Rolnick and Hoops, 1969). Factors that affect the length of the verbal message include sentence length (McMahon, 1963; Weidner and Lasky, 1976) and the number of critical vocabulary elements within a sentence (Shewan and Canter, 1971), both of which have been found to affect auditory comprehension. Gardner et al. (1975) found aphasic subjects to have reduced comprehension performance when length increased from single words to nonredundant sentences containing the same single words. Marshall and Brown (1974) noted retention of sequences of semantically related nouns was affected adversely by message length. Goodglass et al. (1970) found that all of their aphasic subjects were deficient, to some degree, in auditory sequential pointing span (ability to listen to series of nouns and then point, in the same order, to the corresponding pictures). Additionally, Albert (1976) indicated that information load and sequencing deficits are characteristic of aphasia regardless of the clinical type (anterior or posterior). Marshall (1981) suggests these data emphasize the necessity of maintaining control of the auditory stimulus presented to the patient and that patients will generally 
process shorter messages more efficiently than longer messages.

\section{Vocabulary. Schuell and Jenkins (1961) found that} aphasic subjects exhibited a reduction in available vocabulary apparent in all language modalities. Subsequently, Schuell $(1969,1947 \mathrm{~b})$ pointed out that aphasic clients also suffer a reduction of available linguistic rules. She predicted a hierarchical pattern for the recovery of vocabulary and syntax based on frequency of occurrence of these structures in general language usage. Other investigators (Nichols, 1965; Shewan and Canter, 1971) have found that increasing the vocabulary level of a stimulus reduces auditory comprehension in aphasic patients. In general, aphasics are more likely to recognize vocabulary items that have a high frequency of occurrence in their native language (Schuell et al., 1964) and that are meaningful, relevant, and personally significant to the individual (Wepman, 1953; Schuell et al., 1955; Schuell, 1960).

Syntactic complexity. Shewan and Canter (1971) found that syntactic complexity of the spoken message was the most difficult linguistic parameter for most aphasic subjects. Comprehension of messages of increasing syntactic complexity by aphasic subjects has been found to be qualitatively similar, but quantitatively inferior, to that of normal subjects (Parisi and Pizzamiglio, 1970; Shewan and Canter, 1971; Poeck et al., 1972). The importance of syntactical complexity on 
aphasic subjects' auditory comprehension is further illustrated by the fact that, even when lexical comprehension is quite good, sentence interpretation may be impaired because of grammatical processing deficits (Duffy, 1981). Caramaza and Zurif (1976) have found that some aphasics have significant problems when comprehension of a sentence is dependent upon syntax rather than on logical relations expressed by individual semantic elements. They also indicated that clinically diagnosed conduction and Broca's aphasics have considerably more difficulty comprehending reversible sentences (e.g., "The girl that the boy is hitting is tall.") than semantically restrained ones (e.g., "The boy is hitting the tall girl.") implying the presence of significant deficits in grammatical processing. As Duffy (1981) suggests, the syntax and the interaction between syntax and the semanticlogical relationships among the words within a sentence should be considered when devising sentence comprehension tasks.

Aphasic subjects' performance on sentence verification tasks further underscores the importance of syntactic complexity to aphasic subjects' comprehension of verbal stimuli. In a sentence verification task, the subject is required to indicate with a "yes" or "no" response whether a verbally presented sentence accurately describes a given picture. The time taken by the subject to make this judgment is measured. Investigations that have employed sentence verification procedures with aphasic subjects found the subjects to process affirmative statements more rapidly than negative statements 
and false negative statements faster than true negative statements (Davis, 1975; Just, Davis, and Carpenter, 1977; West, Gelfer, and Rosen, 1976).

Other investigations also support the potential effects of syntactic complexity on auditory comprehension. Lasky, Weidner, and Johnson (1976) found that aphasic subjects comprehended active sentences (e.g., "The boy is running.") better than negative sentences (e.g., "The boy is not running."). Similarly, Levy and Taylor (1968) and Shewan and Canter (1971) suggest that aphasics generally appear to comprehend sentences without transformations better than those containing transformations.

Responses of aphasic patients to wh-questions dealing with location and time (e.g., "where" and "when" questions) and questions requiring a name or description of objects or actions (e.g., "what-do," "what-verb," "who," what kind," and "how many" questions) were studied by Gallagher and Guilford (1977). The patients had more difficulty with questions dealing with location and time. These researchers concluded that Wh-elements are not uniform in difficulty and clinicians should be sensitive to these data when designing treatment tasks.

In a recent study, Green and Boller (1974) asked sixteen severely aphasic subjects to respond to commands, yes-no questions, and information questions when such tasks were directly worded (e.g., "Point to the window."), indirectly worded (e.g., "I'd like you to point to the window."), or directly 
worded and preceded by an introductory sentence (e.g., "Here's something now. Point to the window."). They found their subjects responded to the directly worded items with a greater number of appropriate responses as compared to the indirectly worded items. The directly worded items preceded by an introductory sentence were easier than indirectly worded items.

Finally, Goodglass, Blumstein, Gleason, Hyde, Green, and statlender (1979) reported that aphasic subjects were better able to comprehend expanded, noncomplex utterances containing a series of simple propositions (e.g., "The man was greeted by his wife and was smoking a pipe.") than shorter but syntactically more complex utterances (e.g., "The man greeted by his wife, was smoking a pipe."). These data again highlight the complexity of the interactions among stimulus factors and indicate that maximizing the facilitory effect of one factor may increase the difficulty imposed by another. Because variations in the syntactic complexity of language has such profound effects on the aphasic patient's auditory comprehension, they are usually given paramount consideration when structuring auditory stimulation tasks for the treatment programs.

Redundancy. Duffy (1981) and Marshall (1981) point out that the potential detrimental effects of increasing message length may be negated as a function of message redundancy. In general, increased redundancy of a verbal message appears 
to facilitate comprehension. Gardner et al. (1975) found aphasic subjects comprehended semantically redundant sentences such as "The cat is furry." better than non-redundant sentences such as "The cat is nice." or sentences containing semantic detractors (e.g., "The cat is sour.").

Duffy (1981) suggests that the sensitivity of the Token Test to subtle comprehension deficits is due, at least partially, to the non-redundant properties of the verbal stimuli. In this vein, West and Kaufman (1972) observed that the aphasic subjects responded more successfully to certain commands within the Token Test that they designated as maximally redundant (e.g., "Touch the small red circle and the small green circle.") than to those they described as minimally redundant le.g., "Touch the small red circle and the large green square."). In summary, increasing redundancy involves the use of elements in a message that underscore its meaning or reduce the information load placed on the listener. While this process also may affect message length, the beneficial aspects of redundancy tend to outweigh this negative influence (Marshal1, 1981).

Prominence. Marshall (1981) emphasized the factor of prominence in maximizing the aphasic individual's comprehension. This procedure involves the highlighting of critical elements of a verbal message. Darley (1976) notes that auditory comprehension is facilitated by supplying the aphasic subject with a word he can grasp easily and placing the word 
in a prominent position within the verbal message. For example, a statement worded "I need your address." might be easier for an aphasic subject to understand than the question "Would you tell me your address so I can complete your records?" because of the location of the salient word "address." Similarly, Green and Boller (1974) have shown that aphasic subjects respond more appropriately to directly worded commands and commands preceded by an introductory phrase than to indirectly worded commands. Their results provide some support for highlighting portions of messages delivered to aphasic subjects.

\section{Timing Variables}

Schuell et al. (1964) have suggested that slowing the rate of presentation may aid auditory comprehension. A number of studies, in addition to personal accounts of aphasic persons (Buck, 1968; Rolnick and Hoops, 1969; Skelly, 1975), support this suggestion. The present section provides information regarding the timing variables that appear to affect auditory comprehension in aphasia.

Rate reduction. Kelly and steer (1949) found that the average rate of speaking for normal subjects is approximately 150 words per minute. Weidner and Lasky (1976) and Lasky et al. (1976) examined the effects of rate reduction and found that aphasic subjects understood sentence material better at rates of 110 and 120 words per minute that 150 words per minute. Several other investigations (Albert and Bear, 1974; 
Gardner et al., 1975; Cermak and Moreines, 1976) also have found that aphasic subjects' comprehension is improved by slower presentation rates. An interesting finding from an investigation by Salvatore et al. (1975) indicates that experienced clinicians presented Token Test commands to low level aphasic subjects at a slower rate than nonexperienced clinicians, and tended to vary their rate of presentation according to the severity of the patients' aphasia. Unfortunately, clinicians also appear to increase their rate of speech when conversing in more natural communicative situations. Gravel and Lapointe (1982) recently investigated the speech rate of fifty health care professionals during natural social discourse with two aphasic subjects and one normal subject. Even though the health care professionals were informed of the aphasic subjects' comprehension deficits prior to discourse, none of the professionals reduced their rate of speech when conversing with the aphasics. These data emphasize the necessity of presenting verbal stimuli at a slightly slower than normal rate and reminding ourselves, as clinicians, of the importance of this message delivery technique.

Pause use. Pause insertion, according to Marshall (1978), involves the deliberate use of brief pauses, usually at a syntactic boundary to enhance retention and understanding. Salvatore (1975) noted that pauses are the most commonly used technique by which speakers and clinicians reduce their rate of speech in conversations and in giving commands. Aphasic adults' understanding of verbal messages appears to 
be improved when the message includes a one-second intrastimulus pause (a silent pause within the message itself) in comparison to a pause at syntactic boundaries (Lasky et al., 1976). Comprehension is further enhanced when pauses are placed at syntactic boundaries that separate messages into segments of two or fewer bits of information (Liles and Brookshire, 1975). Liles and Brookshire postulate that this process allows aphasic subjects to group components of incoming messages in a manner similar to the process of "chunking" observed in normal individuals (Friedman and Johnson, 1969). They found that aphasic subjects only could store and process message segments containing two or less bits of information in comparison to normal subjects who process longer, meaningful units.

Salvatore (1976) explored the influence of intrastimulus pause durations on aphasic subjects' comprehension. He found that subjects did not respond correctly to commands containing pauses of less than two seconds consistently and that responses to two-second pauses were superior to those for one-half, one-, or four-second pauses. Recently, Salvatore (1979) found that three-second intrastimulus pauses were more successful in facilitating comprehension within treatment sessions. With respect to treatment planning, Marshall (1981) suggests that clinicians experiment with varying pause durations to optimize the individuals' processing of information.

Interstimulus pauses (brief, silent intervals between 
stimulus presentations) also may improve the aphasic patient's comprehension performance. These pauses may be particularly helpful for those patients who have difficulty receiving and processing verbal messages at the same time. Appropriately used interstimulus pauses may prevent errors or perseverative responses (Marshall, 1981).

some investigators have studied the effects of imposed response delay on the comprehension of aphasic subjects (Yorkston et al., 1977; Toppin and Brookshire, 1978; Brookshire, 1976). This involves "forcing" the patient to wait for a few seconds before responding to an auditory stimulus. These data indicate that some, but not all patients benefit from this procedure. The major benefit is that anticipatory errors are prevented, but only if the stimuli can be visualized during the imposed delay. Marshall (1981) suggests that when stimulus items cannot be visualized by aphasics, the imposed delay probably increases the attentional demands and may negatively influence performance. He emphasizes that imposed delay of response should be used on an individual basis.

Alerting signals. As mentioned previously, aphasic individuals with attentional deficits have difficulty processing the initial portion of a message or may miss very short messages entirely. This may be circumvented with the use of alerting signals. Marshall (1981) suggests using introductory words and phrases that are not part of the message itself, as alerting signals. This may "turn on" the patient's 
system to counteract the lack of preparedness. In an unpublished study by Marshall and Thistlethwaite (1977), aphasic subjects' responses to Token Test commands preceded by alerting signals were slightly higher, although not significantly better than those presented without an alerter. Marshall (1981) speculates that aphasic subjects may respond differentially to various alerters, but until this topic is further investigated, selection and use of alerting signals will need to be done on an intuitive and individual basis.

Contextual Variables

All aphasia treatment approaches should have one common functional goal. This involves stimulation of maximal recovery of language functions within the framework of the individual patient's needs, his overall condition and the extent of the irreversible damage that is present (Schuell, 1964). Marshall (1981) points out that one of the more provocative areas of contemporary aphasia research involves the investigation of aphasic subjects' comprehension and expression within their natural communicative environments. The discussion in the following section focuses on the contextual variables that may enhance comprehension in both structured and real-life communicative interactions.

The meanings exchanged during a conversation are derived from the relationship between the linguistic aspects of each utterance and the contextual variables of the situation. It is observed frequently by family members and clinicians that 
many patients are unable to respond with an accurate linguistic indication that they understand a message, but may demonstrate their comprehension in other ways. Marshall (1981) indicates that these individuals often utilize those cues, gestures, expressions, prompts, vocal tones, and other features present in a normal communicative interaction. Results of several previously mentioned studies support this theory. Boller and Green (1972), Green and Boller (1974), and Boller et al. (1979) indicate that aphasic subjects with severely impaired auditory comprehension may appropriately use such contextual elements as head nods, expressions, and gestures to respond to commands, yes/no, and informational questions even if the responses are inaccurate.

A recent study by wilcox et al. (1978) illustrates the importance of contextual elements within the aphasic individual's naturalistic environment. Eighteen aphasic subjects comprehended indirect requests occurring in natural communicative settings significantly better than they understood utterances in standard testing situations. Additional studies (Stachowiak, Huber, Poech, and Kerschensteiner, 1977; Waller and Darley, 1978) also indicate that aphasics are able to understand utterances within a linguistic context much better than would be predicted by their performance on formalized examinations.

In summary, these data suggest that aphasic subjects are more likely to comprehend better in contextually rich, communicative interactions than in structured, controlled 
situations.

Additional Variables

The comprehension of spoken messages by aphasic subjects may be affected by factors other than those elements already described. Additional critical features which may affect auditory comprehension but cannot be conveniently grouped under a specific category are briefly discussed in this section.

Supplemental inputs. Schuell (1964) indicates that a primary goal of aphasia treatment is to ". . make something happen in the patient's brain." This is accomplished by eliciting multiple responses, but this objective cannot always be accomplished through the auditory input channel alone. Aphasic patients with severe auditory processing deficits or those who have lengthy periods of severe auditory imperception may benefit from supplemental inputs (Marshall, 1981). Supplemental inputs may include visual symbols, expressions, gestures, or vocal tones in combination with the auditory stimulus. For example, an aphasic patient may respond poorly to the verbal command "Point to the comb." Combining the printed word "comb" with the auditory stimulus, however, may help. Marshall and stevenson (1977) have suggested the use of supplemental inputs for auditory stimulations with a patient presenting signs of pure word deafness. Supplemental inputs may be useful for severely involved patients early in treatment or until the patient can accurately respond to 
auditory presentations alone. Wertz (1978), however, cautions clinicians in the use of multimodal stimulation. He states that some patients perform better when stimuli are presented unimodally.

Output response. If the clinician is attempting to assess the aphasic patient's ability to understand an incoming verbal message, care should be taken to minimize output response requirements. Patients may respond in several ways, including pointing, gesturing, writing, and speaking. The required mode of response should be that which best allows the patient to demonstrate his comprehension ability and, as Brookshire (1978a) emphasizes, kept as simple as possible.

Stimulus exposures. Marshall (1978) emphasizes the importance of selectively controlling the number of visual stimuli presented to the aphasic adult at one time. Having the patient view too many stimuli may overload his system. Darley (1976) reviewed conditions of stimulus overload and suggests that the number of bits of information the patient must process be limited by controlling the length of the unit and the number of units presented at once. As the patient improves, the size of the stimulus field can increase.

Semantic relatedness. The semantic field surrounding the presented stimulus also may affect auditory processing; aphasic subjects tend to confuse stimuli that are meaningfully associated (Schuell and Jenkins, 1961; Pizzamiglio and 
Appicciafuoco, 1971; Luria, 1972; Goodglass and Baker, 1976; Marshall et al., 1978). In 1974, Marshall and Brown systematically manipulated the degree of semantic relatedness among pictures presented to a group of aphasics and a control group of normal subjects. They concluded that " . . semantic confusions are common in aphasia; aphasics exhibit significantly more of these confusions than nonaphasics."

Task requirements. The level of difficulty of the auditory comprehension task also can have a profound influence on the patient's response. Task difficulty can be hierarchically manipulated in several ways. For example, when using Token Test stimuli, the examiner may present all twenty tokens of various colors, shapes, and sizes; a selected number of tokens; or ask the patient to match like tokens (Marshall, 1981). Brookshire (1978) developed a Token Test battery to assess auditory comprehension and found aphasics' responses were best on visual matching tasks, next best on stimulus recognition from a visual field of four tokens, and poorest on the standard presentation of all twenty tokens.

Several studies (Goldstein, 1948; Darley, Sherman, and Siegal, 1959; Halpern, 1965; Spreen, 1968; Kreindler, Gheroghita, and Voinescu, 1971; Zurif, Caramazza, Myerson, and Galvin, 1974) indicate that the clinician should be aware of the abstractness factor when selecting and ordering stimulus materials; abstract words present more difficulty to aphasic patients than concrete words. 
Finally, the clinician should set task demands which tax but do not exceed the capacity of the aphasic individual's processing system. Appropriately designed treatment activities should improve both the individual's comprehension deficit and decrease additional errors (Brookshire, 1972; Gardner and Brookshire, 1972; and Brookshire, 1976).

Mode of presentation. A final factor that has received relatively little attention in the aphasia literature is mode of presentation. Three modes are currently available to the clinician or researcher for presentation of verbal stimuli in auditory comprehension tasks. Live voice or face-to-face presentations are the most common. Because of the importance of standardization in the delivery of verbal stimulus items, however, tape recorded and more recently videotape recorded presentations also have been employed. Surprisingly, the influence of different modes of presentation on the auditory comprehension of aphasic subjects has not been systematically examined. Only two investigations provide information suggesting that presentation mode might differentially affect aphasics' comprehension. There are no reported studies that have examined the influence of videotaped presentations. In 1974, Green and Boller examined some of the features of rudimentary comprehension that may be preserved in severely impaired aphasic subjects. They found that subjects responded significantly better to spoken than to tape-recorded items, especially when the examiner was seated before them. Boller 
et al. (1979) determined the ability of severely aphasic subjects to comprehend sentences containing either emotional or neutral content when presented directly by the examiner and via a tape recorder. Their results supported the earlier Green and Boller (1974) findings; namely, that when severely aphasic subjects hear sentences spoken directly by the examiner they produce a significantly greater number of appropriate responses than when the same items are presented by a tape recorder.

\section{Summary}

In summary, the studies reviewed in this section suggest that aphasic individuals possess linguistic abilities that are difficult to measure because of input or output limitations that interfere with their demonstration of those linguistic abilities (Brookshire, 1978a). There are many variables, however, which the sophisticated clinician can manipulate in order to heighten or facilitate the aphasic patient's comprehension. 


\section{CHAPTER III}

\section{METHODS AND PROCEDURES}

A description of the subjects, tasks, presentation modes, procedures, and scoring will be presented in this section.

\section{$\underline{\text { Subjects }}$}

Aphasic patients from the Veterans Administration Medical Center, Portland, Oregon, served as subjects for this study. All were less than 75 years of age, right-handed, and had the equivalent of a high school education. All had suffered a thromboembolic stroke of the left hemisphere and were at least one month post ictus. Subjects had normal hearing (25 $\mathrm{dB}$ or better) in at least one ear on pure-tone audiometric testing and demonstrated the ability to recognize the spoken names of the shapes and colors of the experimental stimuli in a screening test.

The Token Test, described by Boller and Vignolo (1966) was utilized as the process of selection of subjects. Thirty aphasic subjects meeting the above-mentioned criteria were administered the first four parts of the Token Test. Each part contains ten commands requiring the subject to manipulate tokens of two shapes (square and circle), five colors (red, blue, yellow, green, and white), and two sizes (big and 
little). Commands in Part II contain three critical elements (e.g., "Touch the large red circle."); Part IV commands contain six critical elements (e.g., "Touch the large yellow circle and the small red square."). On Parts I and III the subject is exposed to only ten large tokens; on Parts II and IV all twenty tokens are used. On the basis of their Token Test performances, twelve subjects were ultimately selected to participate in the experiment and assigned to either a high or low comprehension group.

Six subjects who made no errors on Part I, 30 to 60 percent errors on Part II, and no correct responses (using a plus-minus scoring system) on Parts III or IV of the test comprised the low-comprehension group (LC). The high-comprehension group included 6 subjects who made no errors on Parts I, II, or III and 30 to 60 percent errors on Part IV. Subjects in the LC Group ranged in age from 55 to 75 ( $\bar{x}=62$ months), were from 1 to 208 months post ictus ( $\bar{x}=73$ months), and had overall scores on the Porch Index of Communicative Ability - PICA (Porch, 1967) ranging from the 28 th to the 5 lst percentile $(\bar{x}=42$ nd percentile). HC subjects were between 52 to 66 years of age ( $\bar{x}=59$ years) and from one to 156 months post ictus $(\bar{x}=62$ months $)$. Severity of aphasia, according to PICA overall percentile rankings ranged from the $52 \mathrm{nd}$ to the $87 \mathrm{th}$ percentile $(\overline{\mathrm{x}}=73 \mathrm{rd}$ percentile $)$ for subjects in the high-comprehension group. See Table I. 
TABLE I

DESCRIPTION OF APHASIC SUBJECTS

Subjects Age Sex Duration of aphasia severity*
(months)

Low Comprehension Group

$\begin{array}{lllrl}\# 1 & 75 & M & 104 & (41 \%) \\ \# 2 & 55 & M & 54 & (51 \%) \\ \# 3 & 66 & M & 3 & (28 \%) \\ \# 4 & 56 & M & 2 & (34 \%) \\ \# 5 & 57 & M & 60 & (47 \%) \\ \# 6 & 63 & M & 208 & (50 \%) \\ \bar{X} & 62 & & 73 & (428)\end{array}$

High Comprehension Group

$\begin{array}{lrrrr}\# 1 & 58 & \text { F } & 57 & (87 \%) \\ \# 2 & 52 & \text { F } & 156 & (75 \%) \\ \# 3 & 54 & M & 1 & (80 \%) \\ \# 4 & 66 & M & 156 & (84 \%) \\ \# 5 & 62 & M & 1 & (67 \%) \\ \# 6 & 60 & M & 7 & (52 \%) \\ \bar{X} & 59 & & 62 & (73 \%)\end{array}$

Numbers in brackets indicate overall percentile ranking on Porch Index of Communicative Ability - PICA, (Porch,

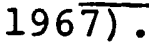




\section{Tasks}

Each subject was administered an abstract and a concrete comprehension task of ten items in the live voice, tape recorded, and videotaped modes of presentation. Abstract tasks consisted of Part II of the Token Test for LC subjects and Part IV of the Token Test for HC subjects (see Appendix A). Tokens were mounted on a 17 inch by 21 inch poster board following guidelines of Boller and Vignolo (see Appendix B). The concrete tasks for both groups were identical to the abstract tasks with the exception that the tokens were replaced with pictures of houses and flowers of equivalent size and color (see Appendices C and D). This procedure has been described by Kreindler et al. (1971) who found that aphasic subjects decoded nouns denoting concrete shapes of flower and house significantly better than abstract shapes of circle and square.

\section{Presentation Modes}

Master tapes were recorded on a Sony TC-110 cassette tape recorder, an Ampex AG-500 magnetic tape recorder, and a Sony VC-2600 videocassette recorder using $3 / 4$ inch tapes and equipped with a Sony AVC 3260 camera for all three presentation modes. To insure equivalency of tape recorded and videotaped stimuli, master tapes were recorded simultaneously following several practice tapings. The difficulties inherent in providing similar live voice presentations to each subject 
were overcome by having the experimenter listen to the master tape through an ear insert transducer connected to a Sony TC110 cassette recorder, and model each command as closely as possible. Presentations were separated by twenty second intervals on the master tapes so as to allow ample time to respond to the command before the next item was presented.

\section{Procedures}

All testing took place in the Speech Pathology Research laboratory at the Portland V.A. Medical Center. Standard arrangement of furniture and equipment was maintained for each presentation. Each experimental task was preceded by a set of standard tape recorded instructions (see Appendix E), followed by three practice trials using items not included in the experimental tasks (see Appendices $A$ and $C$ ). Within each presentation mode, the concrete task was always given first; ordering of presentation modes was counterbalanced across subjects. Stimuli were presented at a comfortable loudness level, and no repetitions of stimulus items were permitted. The administration time for all tasks was approximately thirty minutes per subject.

\section{$\underline{\text { scoring }}$}

Subjects' responses were scored, using both plus-minus and weighted systems. Only the responses to the ten concrete and ten abstract commands were scored. The plus-minus system involved scoring each response as right or wrong. The maximum 
score attainable for each task was ten for both LC Group and HC Group subjects.

In assigning the weighted scores, subjects received from 0 to 6 points, depending on the number of elements of the command they comprehended. On Part II commands, a subject could receive from 0 to 3 points; on Part IV commands, the maximum score was 6 .

\section{Data Analysis}

The plus-minus scores were analyzed with a three-way Analysis of Variance (Winer, 1971). Weighted scores were converted to percentages and analyzed similarly to plus-minus scores. 
CHAPTER IV

RESULTS AND DISCUSSION

$\underline{\text { Results }}$

Two questions were formulated for this study: 1) Does mode of presentation affect low-level aphasic adults' auditory comprehension of abstract and concrete commands? and 2) Does mode of presentation affect high-level aphasic adults' auditory comprehension of abstract and concrete commands? subjects' plus-minus scores are shown in Appendix F. These data were submitted to a three-way Analysis of Variance which considered the effects of presentation mode (live voice, tape recorded, and videotaped); task (concrete versus abstract); groups (low-level versus high-level); and the interactions among these variables. A summary of this analysis is provided in Table II. Subjects' weighted scores are given in Appendix G. A summary of the Analysis of Variance for these scores is shown in Table III.

Analysis of both plus-minus and weighted scores did not show subjects' understanding of verbal commands to be influenced significantly by mode of presentation. In addition, the performance of high-level and low-level groups was not significantly different.

As anticipated, subjects made higher scores on the 
TABLE II

SUMMARY OF ANALYSIS OF VARIANCE

FOR PLUS-MINUS SCORES

\begin{tabular}{|c|c|c|c|c|c|}
\hline $\begin{array}{l}\text { SOURCE OF } \\
\text { VARIATION }\end{array}$ & $\begin{array}{l}\text { SUM OF } \\
\text { SQUARES }\end{array}$ & $\begin{array}{c}\text { DEGREES OF } \\
\text { FREEDOM }\end{array}$ & $\begin{array}{l}\text { MEAN } \\
\text { SQUARE }\end{array}$ & $\mathrm{F}$ & $P$ \\
\hline Between Subjects & 330.9444 & 11 & 30.0858 & 8.1681 & 0.0000 \\
\hline Level & 10.8888 & 1 & 10.8888 & .3402 & 0.5726 \\
\hline Within Subjects & 221.0000 & 60 & 3.6833 & & \\
\hline Mode & 3.1111 & 2 & 1.5555 & .5577 & 0.5811 \\
\hline Mode $x$ Difficulty & .1111 & 2 & .0555 & .0199 & 0.9802 \\
\hline Difficulty & 22.2222 & 1 & 22.2222 & 2.5046 & 0.1445 \\
\hline Level x Difficulty & 1.3888 & 1 & 1.3888 & .1565 & 0.7006 \\
\hline Mode x Difficulty & 8.7777 & 2 & 4.3888 & 2.3235 & 0.1237 \\
\hline $\begin{array}{l}\text { Level } \mathbf{x} \text { Mode } \mathbf{x} \\
\text { Difficulty }\end{array}$ & 3.1111 & 2 & 1.5555 & .8235 & 0.4532 \\
\hline TOTAL & 551.94444 & 71 & & & \\
\hline
\end{tabular}


TABLE III

SUMMARY OF ANALYSIS OF VARIANCE

FOR WEIGHTED SCORES

\begin{tabular}{|c|c|c|c|c|c|}
\hline $\begin{array}{l}\text { SOURCE OF } \\
\text { VARIATION }\end{array}$ & $\begin{array}{l}\text { SUM OF } \\
\text { SQUARES }\end{array}$ & $\begin{array}{l}\text { DEGREES OF } \\
\text { FREEDOM }\end{array}$ & $\begin{array}{l}\text { MEAN } \\
\text { SQUARE }\end{array}$ & $\mathrm{F}$ & $\mathrm{P}$ \\
\hline Between Subjects & 13419.8194 & 11 & 1219.9835 & 55.5871 & 0.0000 \\
\hline Level & 11425.6805 & 1 & 11425.6805 & 57.2963 & 0.0000 \\
\hline Within subjects & 1316.8333 & 60 & 21.9472 & & \\
\hline Mode & 24.1111 & 2 & 12.0555 & .4683 & 0.6327 \\
\hline Mode x Difficulty & 37.4444 & 2 & 18.7222 & .7273 & 0.4955 \\
\hline Difficulty & 159.0138 & 1 & 159.0138 & 5.0726 & $0.0479 *$ \\
\hline Level x Difficulty & 19.0138 & 1 & 19.0138 & .6065 & 0.4541 \\
\hline Mode $x$ Diffuiculty & 3.4444 & 2 & 1.7222 & .1539 & 0.8583 \\
\hline $\begin{array}{l}\text { Level } x \text { Mode } x \\
\text { Difficulty }\end{array}$ & 21.7777 & 2 & 10.8888 & .9731 & 0.3950 \\
\hline TOTAL & 14736.6527 & 71 & & & \\
\hline
\end{tabular}

* $\mathrm{P}<.05$ 
concrete task than the abstract task. This difference was significant for weighted $(F(1,10)=5.07 ; \mathrm{P}<.05)$ but not plus-minus scores. No significant interactions emerged among the study variables for either plus-minus or weighted score analyses.

\section{Discussion}

On the basis of the work of Green and Boller (1974). and Boller et al. (1979), it was anticipated that subjects might respond better to live voice and videotape recorded presentations than to tape recorded presentations. The results of this study, however, did not show either low-level or high-level aphasic subjects' comprehension of commands to be influenced by presentation mode. The fact that aphasic subjects performed significantly better on concrete than abstract commands was anticipated. This is in agreement with the data reported by Kreindler et al. (1971) which indicate that the names of abstract shapes are understood with more difficulty than names of concrete shapes.

The main issue of this study concerned the possible difference in aphasic responses to three presentation modes. There are several potential explanations as to why subjects' understanding of commands was not influenced by mode of presentation.

First of all, precautions were taken to insure that stimuli employed in the three conditions were as identical as possible. This may have successfully negated mode effects 
for subjects in the experiment. Moreover, the experimental tasks of this study involved non-redundant Token Test commands requiring the subject to listen to each command, hold its distinguishing features in short term memory while scanning the token arrangement, and preparing for the movement of the hand in order to execute a pointing response. This process involved attention to stimuli originating from two separate sources: 1) the verbal message; and 2) a display of tokens provided on the table. It is possible that the subjects' attention may have been divided between these two stimuli. Studies reflecting presentation mode differences (Green and Boller, 1974; Boller et al., 1979) employed commands, yes/no, and information questions. This process simply provides auditory information from one source, the examiner. Finally, in these studies the subjects were required to produce a verbal or gestural response. In the present study, only a pointing response was required.

In the conduct of the experiment, the examiner observed that nearly all the subjects attended solely to the token display during live and videotaped presentations when the added benefits of facial expression might have been helpful to them. Methodologically, this tendency might have been curbed by covering the token display until the stimulus had been delivered. Also it is possible that when verbal or gestural responses are not demanded from aphasic persons, they are more likely to focus on visual stimuli and ignore other potentially adjunctive information. 
Another factor that may have contributed to the absence of presentation mode differences is the severity level of the aphasic population sampled. The subjects of the Green and Boller (1974) and Boller et al. (1979) studies were severely aphasic. When this examiner attempted to give the experimental tasks to a severely aphasic individual, he did not respond to 11 consecutive items but simply looked at the examiner and smiled. Subjects participating in the present study demonstrated sufficient comprehension to respond to Part II or Part IV Token Test items and were minimally impaired in auditory comprehension in contextual communicative situations. It is possible that these less severely impaired patients were not sensitive to presentation mode differences. 


\section{CHAPTER V}

\section{SUMMARY AND IMPLICATIONS}

\section{Summary}

This study examined the influence of three presentation modes (live voice, tape recorded, and videotape recorded) on aphasic subjects' comprehension of concrete and abstract commands.

Twelve aphasic adults were assigned to high or low comprehension groups according to their performance on the Token Test described by Boller and Vignolo (1966). Six subjects who committed from 30-60 percent of the items on Part II were placed in the low comprehension group. Six subjects who failed 30-60 percent of the items on Part IV of the test made up the high comprehension group.

Each subject was administered two, ten-item tasks (abstract and concrete) in three presentation modes. The abstract tasks for high comprehension subjects consisted of Part IV of the Token Test, which involved responding to commands requiring the patient to manipulate twenty tokens of two shapes (circle and square), five colors (red, blue, green, white, yellow), and two sizes (big and little). For low comprehension subjects the abstract tasks consisted of Part II of the Token Test which involved responding to commands 
requiring the patient to manipulate only ten tokens. The concrete tasks for both groups of subjects were identical to the abstract tasks with the exception that the tokens were replaced with pictures of houses and flowers of equivalent size and color. For each presentation mode, the concrete tasks were presented first. Ordering of presentation modes was counterbalanced across subjects. Subjects' responses were scored using both plus-minus and weighted systems.

Data were submitted to a three-way Analysis of Variance which considered the effects of groups (low comprehension versus high comprehension), difficulty (abstract versus concrete), presentation mode (live, tape videotaped), and the interactions among these variables. As anticipated, subjects performed significantly better on concrete than abstract commands. Differences between groups, and presentation modes, however, were not significant. Clinical implications emerging from this study are: 1) the Token Test could possibly be delivered via tape recorder to standardize presentation; 2) computerized videotape and audiotape recorded presentations might be efficaciously employed in auditory comprehension training for certain aphasic patients; and 3) the effects of mode of presentation in conjunction with other auditory comprehension facilitators needs to be investigated.

\section{Clinical Implications}

The findings of this study offer some important clinical implications. 
No significant presentation mode differences were noted in the present study. Furthermore, Salvatore, straight, and Brookshire (1975) showed that experienced clinicians using live voice presentations differentially varied their presentation rate commensurate with the severity of the patient's aphasia. Considering these findings, it is feasible to use taped presentations when administering diagnostically sensitive tests like the Token Test in order to standardize delivery and, therefore, allow for a more accurate and reliable assessment of auditory comprehension performance.

A second clinical implication of this study concerns the use of tape recorded and videotape recorded stimuli in computerized auditory comprehension programs. This is not to suggest that recorded stimuli should replace the clinician. For some, but not all patients, however, taped presentations of certain tasks, especially those that require non-verbal responses, may permit more efficient use of the clinician's time.

\section{Research Implications}

The results of this study suggest some meaningful research implications regarding the possible effects of mode of presentation when other facilitators are used during message delivery. There are a variety of facilitators that can be manipulated during message delivery. These include reduced rate, use of pauses and alerting signals, increased message 
redundancy, controlled syntactic complexity to highlight the important elements of the message, and additional supplemental inputs. Perhaps when aphasic subjects' attention is selectively focused in order to take full advantage of these facilitators, presentation mode differences may emerge. Further studies investigating the influence of these variables in conjunction with presentation mode on auditory comprehension performance needs to be systematically examined. 


\section{BIBLIOGRAPHY}

ALBERT, M., Short-term memory and aphasia. Brain and Language, $1976,3,23-33$.

ALBERT, M.L., and BEAR, D., Time to understand: A case study of word deafness with reference to the role of time in auditory comprehension. Brain, 1974, 97, 373-384.

BOLLER, F., COLE, M., VRTUNSKI, P.B., PATTERSON, M., and KIM, Y., Paralinguistic aspects of auditory comprehension in aphasia. Brain and Language, 1979, 7, 164-173.

BOLLER, F., and GREEN, E., Comprehension in severe aphasics. Cortex, $19728,383-394$.

BOLLER, F., KIM, Y., MACK, J., Auditory comprehension in aphasia. In H. Whitaker and H.A. Whitaker (Eds.), studies in Neurolinguistics. New York: Academic Press, 1977 .

BOLLER, F., and VIGNOLO, L.A., Latent sensory aphasia in hemisphere-damaged patients: An experimental study with the Token Test. Brain, 1966, 89, 815-829.

BROOKSHIRE, R.H., The role of auditory functions in the rehabilitation of aphasic individuals. In R.T. Wertz, and M. Collins (Eds.), Clinical Aphasiology: Conference Proceedings. Madison: V.A. Hospital, 1972.

BROOKSHIRE, R.H., Differences in responding to auditory verbal materials among aphasic patients. Acta Symbolica, 1974, $1,1-18$.

BROOKSHIRE, R.H., Effects of task difficulty on sentence comprehension performance of aphasic subjects. Journal of Communication Disorders, 1976, 9, 167-173.

BROOKSHIRE, R.H., An Introduction to Aphasia. Minneapolis: BRK Publishers, 1978a.

BROOKSHIRE, R.H., A Token Test battery for tesing auditory comprehension in brain-injured adults. Brain and Language, $1978 \mathrm{~b}, 6$, 149-157.

BUCK, M., Dysphasia: Professional Guidance for the Family and Patient. Englewood Cliffs, N.J.: Prentice-Hall, 1968 . 
CARAMAZZA, A., and ZURIF, E.B., Dissociation of alogrithmic and heuristic processes in language comprehension: Evidence from aphasia. Brain and Language, 1976, 3, 572-582.

CERMAK, L.S., and MOREINES, J., Verbal retention deficits in aphasic and amnestic patients. Brain and Language, $1976,3,16-27$.

CZVIK, P.S., The application of an auditory approach using nonvariable materials in the treatment of aphasia: Two case studies. In R.H. Brookshire (Ed.), Clinical Aphasiology: Conference Proceedings. Minneapolis: BRK Publishers, 1976 .

DARLEY, F.L., Aphasia: Input and output disturbances in speech and language processing. Presented in dual session on aphasia to the American Speech and Hearing Association, Chicago, Ill., 1969.

DARLEY, F.L., Maximizing input to the aphasic patient. In R.H. Brookshire (Ed.), Clinical Aphasiology: Conference Proceedings. Minneapolis: BRK Publishers, 1976.

DARLEY, F.L., SHERMAN, D., and SIEGAL, G.M., Scaling of abstraction level of single words. Journal of Speech and Hearing Research, 1959, 2, 161-167.

DAVIS, G.A., Psycholinguistic operations in sentence comprehension: Implications for aphasiology. In R.H. Brookshire (Ed.), Clinical Aphasiology: Conference Proceedings. Minneapolis: BRK Publishers, 1975 .

DE RENZI, E., and VIGNOLO, L.A., The Token Test: A sensitive test to detect receptive disturbances in aphasia. Brain, $1962,85,665-675$.

DUFFY, J.R., Schuell's stimulation approach to rehabilitation. In R. Chapey (Ed.), Language Intervention Strategies in Adult Aphasia, 1981.

FRIEDMAN, H.L., and JOHNSON, R.L., Effect of temporal spacing on the recall of time-compressed sentences. In TimeCompressed Speech as an Educational Medium: Studies of Stimulus Characteristics and Individual Differences, 18-41, 1969 .

GALLAGHER, T.M., and GUILFORD, A.M., Wh-questions: Responses by aphasia patients. Cortex, 1977, 13, 44-54.

GARDNER, H., ALBERT, M.L., and WEINTRAUB, S., Comprehending a word: The influence of speech and redundancy on auditory comprehension in aphasia. Cortex, 1975, 11, 155162 . 
GARDNER, B., and BROOKSHIRE, R.H., Effects of unisensory and multisensory presentation of stimuli upon naming by aphasic patients. Language and Speech, 1972, 15, 342357.

GOLDSTEIN, K., Language and Language Disturbances. New York: Grune and Stratton, 1948.

GOODGLASS, H., and BAKER, E., Semantic field, naming, and auditory comprehension in aphasia. Brain and Language, $1976,3,339-374$.

GOODGLASS, H., BLUMSTEIN, S.E., GLEASON, J.B. HYDE, M., GREEN, E., and STATLENDER, S., The effect of syntactic encoding on sentence comprehension in aphasia. Brain and Language, 1979, 7, 201-209.

GOODGLASS, H., GLEASON, J., and HYDE, M., Some dimensions of auditory comprehension in aphasia. Journal of Speech and Hearing Research, $1970,13,595-606$.

GRAVEL, J., and LA POINTE, L.L., Rate of Speech of health care providers during interactions with aphasic and non-aphasic individuals. Paper presented to the Twelfth Annual Clinical Aphasiology Conference, Oshkosh, Wisconsin, 1982 .

GREEN, E., and BOLLER, R., Features of auditory comprehension in severely impaired aphasics. Cortex, 1974, 10, 133145 .

HACAEN, H., Essai de dissociation du syndrome de l'aphasie sensorielle. Rev. Neurol., 1969, 120, 229-237.

HALPERN, H., Effect of stimulus variables on dysphasic verbal errors. Perceptual Motor Skills, 1965, 21, 291-298.

HOLLAND, A.L., and SONDERMAN, J.C., Effects of a program based on the Token Test for teaching comprehension skills to aphasics. Journal of Speech and Hearing Research, 1974, $4,589-598$.

JOHNSON, J., SOMMERS, R., and WEIDNER, W., Dichotic ear preference in aphasia. Journal of Speech and Hearing Research, $1977,20,11 \overline{6-129}$

JUST, M.A., DAVIS, G.A. and CARPENTER, P.A., A comparison of aphasic and normal adults in a sentence-verification task. Cortex, 1977, 13, 402-423.

KELLY, J.C., STEER, J.D., Revised concept of rate. Journal of Speech and Hearing Disorders, 1949, 14, 222-227. 
KREINDLER, A., GHEORGHITA, N., VOINESCU, I., Analysis of verbal reception of a complex order with three elements in aphasics. Brain, 1971, 94, 375-386.

KUSHNER, D., and WINITZ, H., Extended comprehension practice applied to an aphasic patient. Journal Speech and Hearing Disorders, 1977, 42, 296-306.

LA POINTE, L.L., HORNER, J., and LIEBERMAN, R., Effects of ear presentation and delayed response on the processing of Token Test commands. In R.H. Brookshire (Ed.), Clinical Aphasiology Conference Proceedings, Minneapolis: BRK Publishers, 1977.

LASKY, E.Z., WEIDNER, W.E., and JOHNSON, J.P., Influence of linguistic complexity, rate of presentation, and interphrase pause time on auditory-verbal comprehension of adult aphasic patients. Brain and Language, 1976, 3, 386-395.

LEVY, C., and TAYLOR, L.L., Transformational complexity and comprehension in adult aphasics. Paper presented at the Annual Convention of the American Speech and Hearing Association, Denver, 1968.

LILES, B.Z., and BROOKSHIRE, R.B., The effects of pause time on the auditory comprehension of aphasic subjects. Journal of Communication Disorders, 1975, 8, 221-235.

LURIA, A.R., Higher Cortical Functions in Man. New York: Basic Books, 1966 .

LURIA, A.R., Aphasia reconsidered. Cortex, 1972, 8, 34-40.

MARIE, P., Reveision de la question de l'aphasie: l'aphasie de 1861 a 1866: essai de critique historique sur la genesede la doctrine de Broca. Sem. Med., 1906, 26, 565-571.

MARSHALL, R.C., Clinician Controlled Auditory Stimulation for Aphasic Adults. Beaverton: CC Publications, Inc., 1978.

MARSHALL, R.C., Heightening auditory comprehension for aphasic patients. In R. Chapey (Ed.), Language Intervention Strategies in Adult Aphasia, Baltimore: Williams and Wilkins, 1981 .

MARSHALI, R.C., and BROWN, L.J., Effects of semantic relatedness upon the verbal retention of aphasic adults. In B. Porch (Ed.), Proceedings of the Conference on Clinical Aphasiology. New Orleans: B. Porch Publisher, 1974 . 
MARSHALL, R.C., JEFFRIES, E.C., RAU, M.T., GOLPER, L.A., and THOMAS, J., Intermittent auditory imperception: Clinical characteristics and implications for treatment. In R.H. Brookshire (Ed.), Clinical Aphasiology: Conference Proceedings. Minneapolis: BRK Publishers, 1976.

MARSHALL, R.C., KUSHNER, D., and PHILLIPS, D., Letter recognition ability of aphasic subjects. Perceptual Motor Skills, 1978, 47, 1231-1238.

MARSHALL, R.C. and STEVENSON, S., Pure word deafness: Fact or fiction. In R.H. Brookshire (Ed.), Clinical Aphasiology: Conference Proceedings. Minneapolis: BRK Publishers, 1977.

MARSHALL, R.C., and THISTLETHWAITE, N., Verbal and non-verbal alerters: Effects on auditory comprehension of aphasic subjects. Unpublished manuscript, 1977.

MC MAHON, L., Grammatical analysis as part of understanding a sentence. Doctoral Dissertation, Boston: Harvard University, 1963.

MC NEIL, M., DARLEY, F.L., ROSE, D.E., and OLSEN, W.O., Effects of selective binaural intensity variations on auditory processing in aphasia. Paper presented to the Ninth Annual Clinical Aphasiology Conference, Phoenix, Arizona, 1979.

NICHOLS, A.C., Effects of three aspects of sentence structure on immediate recall. Speech Monographs, 1965, 32, 164168 .

PARISI, D., and PIZZAMIGLIO, L., Syntactic comprehension in aphasia. Cortex, 1970, 6, 204-215.

PIZZAMIGLIO, L., and APPICCIAFUOCO, A., Semantic comprehension in aphasia, Journal of Communication Disorders, $1971,3,280-288$.

POECK, K., KERSCHUNSTEINER, M., and HARTJE, W. , A quantitative study on language understanding in fluent and nonfluent aphasia. Cortex, 1972, 8, 299-304.

PORCH, B.E., Porch Index of Comnunication Ability. Palo Alto: Consulting Psychologists, 1967.

RIEDEL, K., Auditory Comprehension in Aphasia. In M.T. Sarno (Ed.), Acquired Aphasia, New York: Academic Press, 1981 .

ROLNICK, M., and HOOPS, H.R., Aphasia as seen by the aphasic. Journal of Speech and Hearing Disorders, 1969, 34, 48-53. 
SALVATORE, A., The effects of pause duration on sentence comprehension of aphasic individuals. Paper presented at the Annual Convention of the American Speech and Hearing Association, Washington, D.C., 1975.

SALVATORE, A.O., Training an aphasic adult to respond appropriately to spoken commands by fading pause duration within commands. In R.H. Brookshire (Ed.), Clinical Aphasiology: Conference Proceedings. Minneapolis: BRK Publishers, 1976.

SALVATORE, A., Clinical treatment of auditory comprehension deficits in acute and chronic aphasic adults: An experimental analysis of within-message pause duration. Paper presented at the Ninth Annual Clinical Aphasiology Conference, Phoenix, Arizona, 1979.

SALVATORE, A., STRAIGHT, M., and BROOKSHIRE, R.H., Effects of patient characteristics on delivery of Token Test commands by experienced and inexperienced examiners. In R.H. Brookshire (Ed.), Clinical Aphasiology: Conference Proceedings. Minneapolis: BRK Publishers, 1975.

SCHUELL, H.M., Auditory impairment in aphasia: Significance of retraining techniques. Journal of Speech and Hearing Disorders, $1953,18,14-21$.

SCHUELL, H.M., Clinical observations on aphasia. Neurology, $1954,4,179-189$.

SCHUELL, H., Minnesota Test for Differential Diagnosis of Aphasia. Minneapolis: University of Minnesota Press, 1965.

SCHUELL, H., Aphasia in adults. In Human Communication and Its Disorders, NINDS Monograph No. 10. Washington, D.C., U.S. Dept. of Health, Education, and Welfare, National Institutes of Health, 1969.

SCHUELL, H., Clinical symptoms of aphasia. In L.F. Sies (Ed.), Aphasia Theory and Therapy: Selected Lectures and Papers of Hildred Schuell. Baltimore, Md., University Park Press, 1974a.

SCHUELL, H., A theoretical framework for aphasia. In L.F. Sies (Ed.), Aphasia Theory and Therapy: Selected Lectures and Papers of Hildred Schuell. Baltimore, Md., University Park Press, $1974 \mathrm{~b}$.

SCHUELL, H.M., CARROLL, V., and STREET, B.S., Clinical treatment of aphasia. Journal of Speech and Hearing Disorders, $1955,20,43-53$. 
SCHUELL, H.M., and JENKINS, J.J., Reduction of vocabulary in aphasia. Brain, 1961, 84, 243-261.

SCHUELL, H.M., JENKINS, J.J., and JIMINEZ-PABON, E., Aphasia in Adults: Diagnosis, Prognosis, and Treatment. New York: Harper and Row, 1964.

SCHUELL, H.M., and SEFER, J., A year of aphasia therapy: A case study. British Journal of Disorders of Communication, $1969,473-482$.

SHEWAN, C.M., and CANTER, G.J., Effects of vocabulary, syntax, and sentence length on auditory comprehension in aphasic patients. Cortex, 1971, 7, 209-226.

SIES, L.F., Aphasia Theory and Therapy: Selected Lectures and Papers of Hildred Schuell. Baltimore, University Park Press, 1974 .

SKELLY, M., Aphasic patients talk back. American Journal of Nursing, $1975,75,1140-1142$.

SPARKS, R., GOODGLASS, H., and NICKEL, D., Ipsilateral versus contralateral extinction in dichotic listening resulting from hemisphere lesions. Cortex, 1970, 8, 249-260.

SPREEN, O., Psycholinguistic aspects of aphasia. Journal of Speech and Hearing Research, 1968, 11, 467-480.

STACHOWIAK, F.J., HUBER, W., POECH, K., and KERSCHENSTEINER, M., Text comprehension in aphasia. Brain and Language, $1977,4,177-195$.

TOPPIN, C.J., and BROOKSHIRE, R.H., Effects of response delay and token relocation on Token Test performance of aphasic subjects. Journal of Communication Disorders, 1978, $11,65-78$.

WALLER, M.R., and DARLEY, F.L., The influence of context on the auditory comprehension of paragraphs by aphasic subjects. Journal of Speech and Hearing Research, 1978, $21,732-745$.

WEIDNER, W.E, and LASKY, E.Z., The interaction of rate and complexity of stimulus on the performance of adult aphasic subjects. Brain and Language, 1976, 3, 34-40.

WEISENBERG, T.H., and MC BRIDE, K.E., Aphasia. New York: Commonwealth Fund, 1935.

WEPMAN, J.M., A conceptual model for the process involved in recovery from aphasia, Journal of Speech and Hearing Disorders, 1953, 18, 4-13. 
WEPMAN, J.M., Aphasia therapy: A new look. Journal of Speech and Hearing Disorders, $1972,37, \frac{203-214 .}{}$

WERTZ, R.T., Neuropathologies of Speech and Language: An introduction to patient management. In D.F. Johns (Ed.), Clinical Management of Neurogenic Communicative Disorders. Boston: Little, Brown and Co., 1978.

WEST, J.A., Auditory comprehension in aphasic adults: Improvement through training. Archives of Physical Medicine and Rehabilitation, 1973, 54, 78-86.

WEST, J.A., GELFER, C.E., ROSEN, J.S., Processing of true and false affirmative sentences by aphasic subjects. In R.H. Brookshire (Ed.), Clinical Aphasiology: Conference Proceedings. Minneapolis: BRK Publishers, 1976.

WEST, J.A., and KAUFMAN, G.A., Some effects of redundancy on the auditory comprehension of adult aphasics. Paper presented at the Annual Convention of the American Speech and Hearing Association, San Francisco, 1972.

WILCOX, M.J., and DAVIS, G.A., and LEONARD, L.B., Aphasics' comprehension of contextually conveyed meaning. Brain and Language, $1978,3,362-377$.

WINER, B.J., Statistical Principles in Experimental Design. New York: McGraw-Hill, 1971.

YORKSTON, K.M., MARSHALL, R.C., and BUTLER, M.R., Imposed delay of response: Effects on aphasics' auditory comprehension of visually and non-visually cued material. Perceptual Motor Skills, 1977, 44, 647-655.

ZURIF, E., CARAMAZZA, A., MYERSON, R., and GALVIN, J., Semantic feature representations for normal and aphasic language. Brain and Language, 1974, 1, 167-187. 
APPENDIX A

\section{ABSTRACT COMMANDS *}

\section{Low Comprehension Group}

\begin{tabular}{|c|c|c|c|c|}
\hline $\begin{array}{l}\text { (Practice } \\
\text { Commands) }\end{array}$ & $\left\{\begin{array}{l}\text { A) } \\
\text {, B) } \\
\text { C) }\end{array}\right.$ & $\begin{array}{l}\text { Touch } \\
\text { Touch } \\
\text { Touch }\end{array}$ & $\begin{array}{l}\text { the } \\
\text { the } \\
\text { the }\end{array}$ & $\begin{array}{l}\text { little red circle } \\
\text { little white circle } \\
\text { big red square }\end{array}$ \\
\hline & $\begin{array}{l}\text { 1) } \\
\text { 2) } \\
3 \text { ) } \\
4) \\
5) \\
6) \\
7 \text { ) } \\
8 \text { ) } \\
9) \\
\text { 10) }\end{array}$ & $\begin{array}{l}\text { Touch } \\
\text { Touch } \\
\text { Touch } \\
\text { Touch } \\
\text { Touch } \\
\text { Touch } \\
\text { Touch } \\
\text { Touch } \\
\text { Touch } \\
\text { Touch }\end{array}$ & $\begin{array}{l}\text { the } \\
\text { the } \\
\text { the } \\
\text { the } \\
\text { the } \\
\text { the } \\
\text { the } \\
\text { the } \\
\text { the } \\
\text { the }\end{array}$ & $\begin{array}{l}\text { little yellow circle } \\
\text { big green circle } \\
\text { big yellow circle } \\
\text { big blue square } \\
\text { little green circle } \\
\text { big red circle } \\
\text { big white square } \\
\text { little blue circle } \\
\text { little green square } \\
\text { big blue circle }\end{array}$ \\
\hline
\end{tabular}

\section{High Comprehension Group}

(Practice) A) Touch the big yellow circle and the big red Commands)

) B) Touch the little green circle and the big white square

) C) Touch the big red square and the little blue circle

1) Touch the little yellow circle and the big green square

2) Touch the little blue square and the little green circle

3) Touch the big white square and the big red circle

4) Touch the big blue square and the big red square

5) Touch the little blue square and the little yellow circle

6) Touch the little blue circle and the little red circle

7) Touch the big blue square and the big green square 
8) Touch the big blue circle and the big green circle

9) Touch the little red square and the little yellow circle

10) Touch the little white square and the big red square

* Stimuli taken from Part II and Part IV of the Token Test (Boller and Vignolo, 1966). 

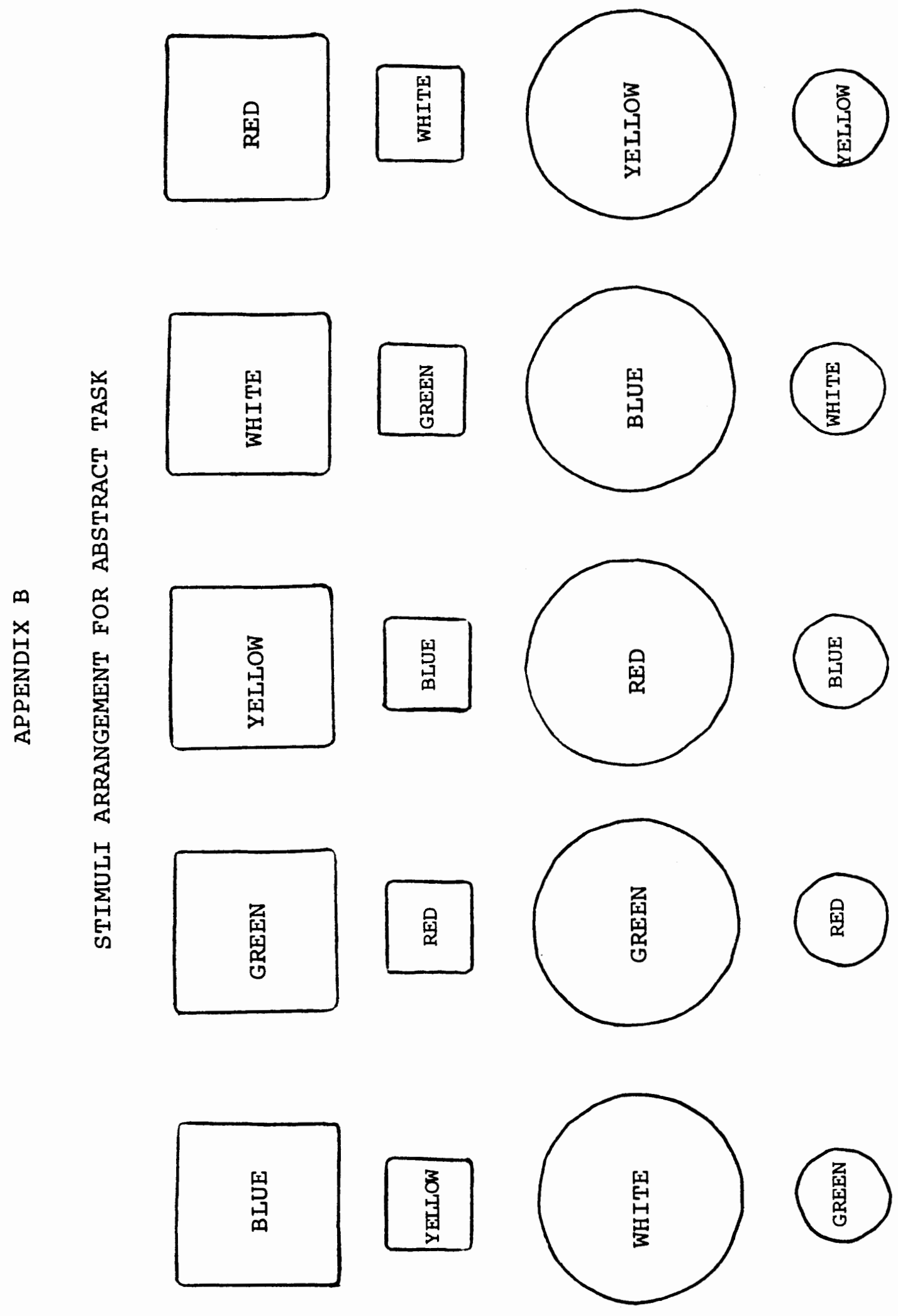
APPENDIX C

CONCRETE COMMANDS

\section{Low Comprehension Group}

(Practice) A) Touch the little red flower

Commands) ) B) Touch the little white flower

) C) Touch the big red house

1) Touch the little yellow flower

2) Touch the big green flower

3) Touch the big yellow flower

4) Touch the big blue house

5) Touch the little green flower

6) Touch the big red flower

7) Touch the big white house

8) Touch the little blue flower

9) Touch the little green house

10) Touch the big blue flower

\section{High Comprehension Group}

(Practice, A) Touch the big yellow flower and the big red Commands)

) B) Touch the little green flower and the big white house

) C) Touch the big red house and the little blue flower

1) Touch the little yellow flower and the big green house

2) Touch the little blue house and the little green flower

3) Touch the big white house and the big red flower

4) Touch the big blue house and the big red house

5) Touch the little blue house and the little yellow flower

6) Touch the little blue flower and the big green house

7) Touch the big blue house and the big green house 
8) Touch the big blue flower and the big green flower

9) Touch the little red house and the little yellow flower

10) Touch the little white house and the big red house 


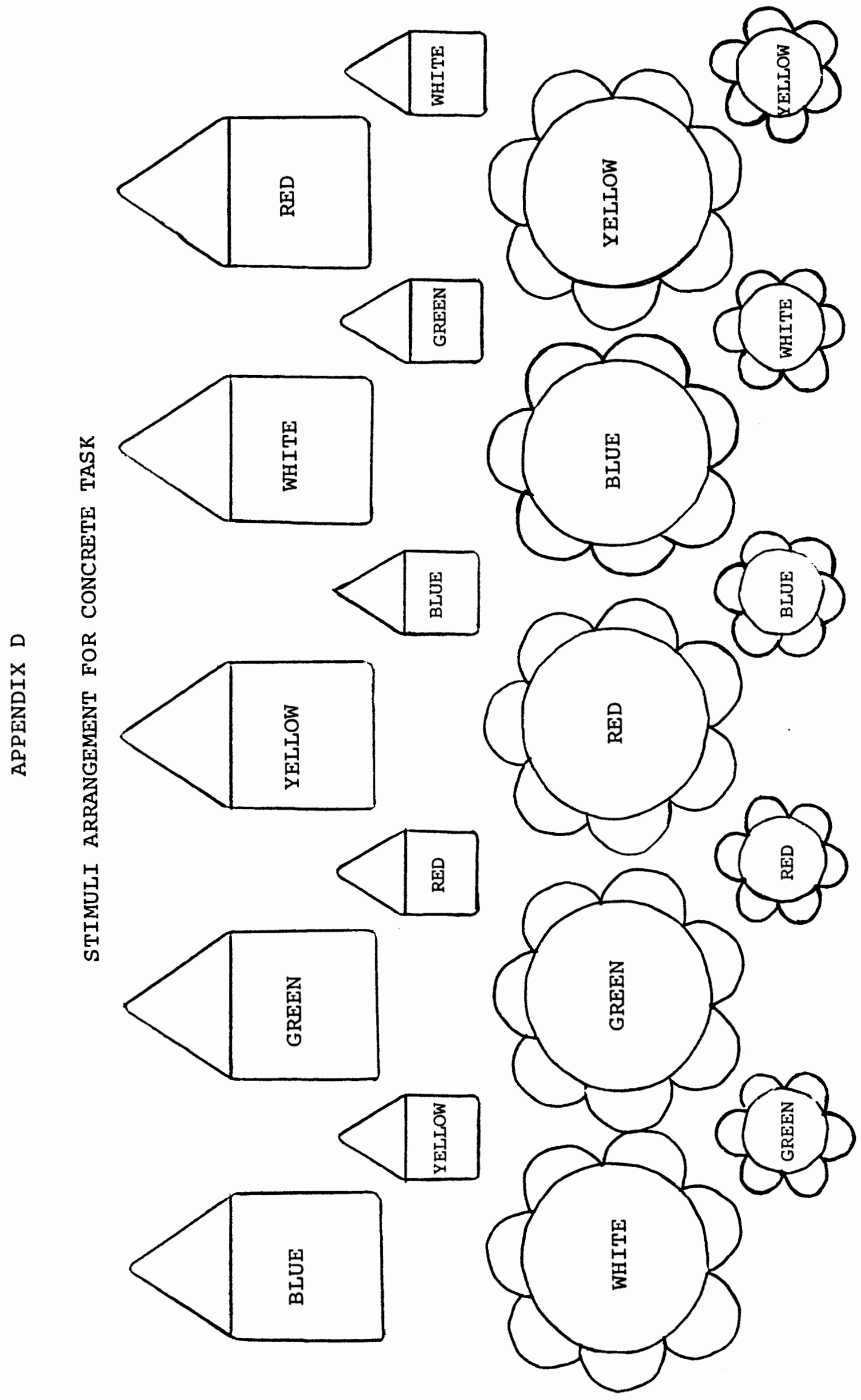


APPENDIX E

TRANSCRIPT OF VERBAL INSTRUCTIONS

INSTRUCTIONS PRECEDING CONCRETE STIMULI:

Hello, I'd like you to take a look at all the pictures on the table in front of you. Can you see all the flowers and houses? Notice that some are big, some are little, and there are different colors, too. I'm going to give you instructions asking you to touch some of the pictures. I'll give each instruction only once. Take your time and select a picture and then wait until my next instruction. Do the best you can. Are you ready?

INSTRUCTIONS PRECEDING ABSTRACT STIMULI:

Hello, I'd like you to take a look at all the pictures on the table in front of you. Can you see all the circles and squares? Notice that some are big, some are little, and there are different colors, too. I'm going to give you instructions asking you to touch some of the pictures. I'll give each instruction only once. Take your time and select a picture and then wait until my next instruction. Do the best you can. Are you ready? 


\section{APPENDIX F}

PLUS-MINUS SCORES AND MEANS OF SUBJECTS'

RESPONSES FOR THREE PRESENTATION MODES*

\begin{tabular}{|c|c|c|c|c|c|c|}
\hline & TaE & & Videc & taped & & \\
\hline & Con. & Abs. & Con. & Abs. & Con. & Abs. \\
\hline \multicolumn{7}{|l|}{ Low Comp. } \\
\hline$\# 1$ & 5 & 6 & 7 & 5 & 8 & 9 \\
\hline$\# 2$ & 9 & 9 & 6 & 10 & 4 & 9 \\
\hline$\# 3$ & 4 & 3 & 3 & 1 & 2 & 3 \\
\hline$\# 4$ & 3 & 2 & 4 & 0 & 2 & 1 \\
\hline$\# 5$ & 7 & 4 & 8 & 4 & 7 & 3 \\
\hline$\# 6$ & 4 & 5 & 6 & 2 & 6 & 4 \\
\hline$\overline{\mathrm{x}}$ & 5.33 & 4.83 & 5.67 & 3.67 & 4.83 & 4.83 \\
\hline \multicolumn{7}{|l|}{ High Comp. } \\
\hline$\# 1$ & 8 & 2 & 10 & 4 & 5 & 7 \\
\hline$\# 2$ & 2 & 2 & 0 & 0 & 1 & 2 \\
\hline \#3 & 6 & 8 & 2 & 7 & 7 & 9 \\
\hline$\# 4$ & 7 & 4 & 7 & 2 & 6 & 4 \\
\hline$\# 5$ & 2 & 0 & 2 & 1 & 2 & 0 \\
\hline$\# 6$ & 8 & 4 & 7 & 4 & 4 & 1 \\
\hline $\bar{x}$ & 5.50 & 3.53 & 4.67 & 3.00 & 4.17 & 3.83 \\
\hline
\end{tabular}

* Maximum score for each task was 10. 